\title{
Propionate inactivation of butane monooxygenase activity in 'Pseudomonas butanovora': biochemical and physiological implications
}

\author{
Correspondence \\ Peter J. Bottomley \\ Peter.Bottomley@ \\ oregonstate.edu
}

Received 26 March 2007

Revised 27 June 2007

Accepted 24 July 2007

\author{
D. M. Doughty, ${ }^{1}$ K. H. Halsey, ${ }^{2,3}$ C. J. Vieville, ${ }^{3}$ L. A. Sayavedra-Soto, ${ }^{3}$ \\ D. J. Arp ${ }^{3}$ and P. J. Bottomley ${ }^{1,4}$
}

\author{
${ }^{1}$ Department of Microbiology, Oregon State University, Corvallis, OR 97331-3804, USA \\ ${ }^{2}$ Program of Molecular and Cellular Biology, Oregon State University, Corvallis, OR 97331-3804, \\ USA \\ ${ }^{3}$ Department of Botany and Plant Pathology, Oregon State University, Corvallis, \\ OR 97331-3804, USA \\ ${ }^{4}$ Department of Crop and Soil Science, Oregon State University, Corvallis, OR 97331-3804, USA
}

\begin{abstract}
Butane monooxygenase (BMO) catalyses the oxidation of alkanes to alcohols in the alkane-utilizing bacterium ' $P$ seudomonas butanovora'. Incubation of alkane-grown ' $P$. butanovora' with butyrate or propionate led to irreversible time- and $\mathrm{O}_{2}$-dependent loss of BMO activity. In contrast, BMO activity was unaffected by incubation with lactate or acetate. Chloramphenicol inhibited the synthesis of new BMO, but did not change the kinetics of propionate-dependent $\mathrm{BMO}$ inactivation, suggesting that the propionate effect was not simply due to it acting as a repressor of $\mathrm{BMO}$ transcription. BMO was protected from propionate-dependent inactivation by the presence of its natural substrate, butane. Although both the time and $\mathrm{O}_{2}$ dependency of propionate inactivation of $\mathrm{BMO}$ imply that propionate might be a suicide substrate, no evidence was obtained for $\mathrm{BMO}$-dependent propionate consumption, or ${ }^{14} \mathrm{C}$ labelling of $\mathrm{BMO}$ polypeptides by $\left[2-{ }^{14} \mathrm{C}\right]$ propionate during inactivation. Propionate-dependent $\mathrm{BMO}$ inactivation was also explored in mutant strains of ' $P$. butanovora' containing single amino acid substitutions in the $\alpha$-subunit of the BMO hydroxylase. Propionate-dependent BMO inactivation in two mutant strains with amino acid substitutions close to the catalytic site differed from wild-type (one was more sensitive and the other less), providing further evidence that propionate-dependent inactivation involves interaction with the BMO catalytic site. A putative model is presented that might explain propionate-dependent inactivation of BMO when framed within the context of the catalytic cycle of the closely related enzyme, soluble methane monooxygenase.
\end{abstract}

\section{INTRODUCTION}

Bacterial monooxygenase enzymes have been extensively studied because of their potential to degrade environmental pollutants, and to serve as biocatalysts for the creation of industrially important chemicals (Astier et al., 2003; Lipscomb, 1994; Smith et al., 2003; Smith \& Dalton, 2004). In this connection we have studied the transcriptional and physiological regulation of butane monooxygenase (BMO) in 'Pseudomonas butanovora'. BMO oxidizes n-alkanes $\mathrm{C}_{2}$ to $\mathrm{C}_{9}$ to alcohols, which are subsequently metabolized to fatty acids (Arp, 1999; Doughty et al., 2006). We have shown that the activity of the bmo promoter is induced by alcohol, aldehyde and epoxide products of alkane and alkene oxidation, and repressed by

Abbreviations: $\mathrm{BMO}$, butane monooxygenase; $\mathrm{MMOH}$, methane monooxygenase hydroxlyase; sMMO, soluble methane monooxygenase. micromolar concentrations of propionate (Doughty et al., 2005, 2006; Sayavedra-Soto et al., 2001, 2005). Furthermore, although the organic acids acetate, propionate, butyrate and lactate can act as exogenous sources of reductant to stimulate BMO activity, propionate and butyrate do not sustain linear rates of BMO activity for as long as equivalent amounts of lactate or acetate (Doughty et al., 2005). In this study our observations were extended to show that propionate and butyrate inactivate pre-existing BMO.

BMO shares a high level of amino acid sequence identity with the well-characterized soluble methane monooxygenase (sMMO) found in methanotrophic bacteria (Sluis et al., 2002). Inhibitors and inactivators of sMMO include (i) suicide substrates such as terminal alkynes, which covalently bind to active-site residues following a catalytic transformation in the enzyme's active site (Prior \& Dalton, 1985); (ii) heavy metals (e.g. $\mathrm{Cu}^{2+}$ ) that rapidly and 
irreversibly inhibit the reductase subunit of the enzyme, preventing electron transfer to the hydroxylase subunit (Green et al., 1985; Jahng \& Wood, 1996); and (iii) $\mathrm{H}_{2} \mathrm{O}_{2}$, which inactivates the enzyme through an unknown mechanism (Astier et al., 2003). Because propionate lacked structural similarity to any of the known inhibitors and inactivators of sMMO mentioned above, we thought it worthwhile to characterize the effect of propionate on BMO. As the project evolved, it became clear that intermediate chain-length fatty acids might be potentially useful for further studies focused on dissecting the catalytic mechanism of BMO.

\section{METHODS}

Bacterial strains, growth conditions and enzyme assays. Wildtype and mutant strains of ' $P$. butanovora' (ATCC 43655) were grown as described previously (Arp, 1999; Hamamura et al., 1999; Vangnai \& Arp, 2001). Cells were harvested by sedimentation in a centrifuge (6500 $\mathrm{g}$ for $10 \mathrm{~min}$ ), and washed three times in $50 \mathrm{mM}$ sodium/ potassium phosphate buffer, $\mathrm{pH}$ 7.1. Lactate-supported, ethenedependent ethene oxide production is a convenient measure of BMO activity. Ethene oxide assays were performed as described previously (Doughty et al., 2005) except that $0.5 \mathrm{ml}$ samples of the headspace were taken at $2.5 \mathrm{~min}$ intervals and injected into separate $7 \mathrm{ml}$ sealed vials for later analysis. This variation of the assay allowed for the prompt sampling of a large number of vials and separated experimental execution from the analysis of gas samples. Protein concentrations were determined using the micro-biuret assay described previously (Gornall et al., 1949).

In vivo inactivation of BMO in 'P. butanovora'. Butane-grown cultures of ' $P$. butanovora' were harvested and washed as described above. Vials $(160 \mathrm{ml})$ containing $80 \mathrm{ml}$ of cells $\left(\mathrm{OD}_{600} 0.5 ; 0.2 \mathrm{mg}\right.$ protein $\mathrm{ml}^{-1}$ ), resuspended in $50 \mathrm{mM}$ sodium/potassium phosphate buffer, served as the reaction chambers for the assays. Vials received $10 \mathrm{mM}$ lactate as an exogenous reductant to support BMO activity and $10 \mathrm{mM}$ of either propionate, butyrate or acetate. Assay mixtures were shaken on an orbital shaker at 200 r.p.m. and $30{ }^{\circ} \mathrm{C}$. Accurate assessment of time-dependent inactivation of BMO required the prompt interruption of the assay. To accomplish this, aliquots of cells were injected into 'stop vials' (160 ml) containing $10 \mathrm{ml} 50 \mathrm{mM}$ sodium/ potassium phosphate buffer in equilibrium with headspace containing $0.4 \mathrm{mmol}$ butane gas (approx. $200 \mu \mathrm{M}$ aqueous concentration), which prevented further inactivation of the BMO enzyme during the washing procedure. Cells were washed three times by centrifugation (6500 $\mathrm{g}$ for $10 \mathrm{~min}$ ), resuspended in $50 \mathrm{mM}$ sodium/ potassium phosphate buffer, and tested for residual BMO activity using the lactate-dependent ethene oxidation assay described above.

Because substrate oxidation by BMO is dependent upon $\mathrm{O}_{2}$ as a cosubstrate, we also examined the effect of propionate on BMO under anoxic conditions. Vials $(160 \mathrm{ml})$ containing $30 \mathrm{ml}$ of $50 \mathrm{mM}$ sodium/potassium phosphate buffer were sealed with butyl rubber stoppers and made anoxic by flushing the headspace with argon for 2 min. Stock solutions of lactate and propionate, as well as cell suspensions, were prepared using the same method. Lactate $(10 \mathrm{mM})$, propionate $(10 \mathrm{mM})$ and cell suspensions were injected into the reaction vial with an airtight syringe. Aliquots were removed from each treatment and injected into 'stop' vials, washed three times, and tested for BMO activity as described earlier.

Investigation of propionate-dependent inactivation in mutant strains of ' $\boldsymbol{P}$. butanovora' with modified BMO hydroxylase. Amino acid sequence alignments were used to compared the hydroxylase subunit of BMO with the hydroxylase subunit $(\mathrm{MMOH})$ of the well-characterized sMMO enzymes of Methylococcus capsulatus (Bath) and Methylosinus trichosporium OB3b (Halsey et al. 2006). Amino acid residues were identified that were likely associated with (a) the active site, (b) entry of substrate into the active site, or (c) the interaction between the hydroxylase subunit and a regulatory subunit, $\mathrm{BmoB}$. These amino acid residues were targeted for site-directed mutagenesis and are described in Table 1. The mutants were screened for sensitivity to propionate as described above.

Labelling studies with ${ }^{\mathbf{1 4}} \mathbf{C}_{\mathbf{2}} \mathbf{H}_{\mathbf{2}}$ and $\left[2-{ }^{\mathbf{1 4}} \mathbf{C}\right]$ propionate. ${ }^{14} \mathrm{C}_{2} \mathrm{H}_{2}$ was synthesized from $\mathrm{Ba}^{14} \mathrm{CO}_{3}\left[57 \mathrm{mCi} \mathrm{mmol}^{-1}\left(2.1 \mathrm{GBq} \mathrm{mmol}^{-1}\right)\right]$ as described previously (Hyman \& Arp, 1992), and $\left[2-{ }^{14} \mathrm{C}\right]$ propionate $\left[50 \mathrm{mCi} \mathrm{mmol}^{-1}\left(1.8 \mathrm{GBq} \mathrm{mmol}^{-1}\right)\right.$ ] was purchased from American Radiolabelled Chemicals. Butane-grown cells were harvested and washed with $50 \mathrm{mM}$ sodium/potassium phosphate buffer containing $50 \mu \mathrm{g}$ chloramphenicol $\mathrm{ml}^{-1}$ to stop the synthesis of protein. Vials $(2 \mathrm{ml}$ ) containing $200 \mu \mathrm{l}$ of resuspended cells (approx. $140 \mu \mathrm{g}$ protein) received $10 \mathrm{mM}$ lactate to serve as an electron donor for BMO activity and $0.2 \mu \mathrm{mol}(1 \mathrm{mM})$ of either $\left[2-{ }^{14} \mathrm{C}\right]$ propionate or ${ }^{14} \mathrm{C}_{2} \mathrm{H}_{2}$. All treatments were incubated for $30 \mathrm{~min}$ in a covered water bath shaker $\left(30{ }^{\circ} \mathrm{C}\right.$ and 150 r.p.m.). Following incubation, cells were washed three times in $50 \mathrm{mM}$ sodium/potassium phosphate buffer and lysed by the addition of SDS and DTT (Sambrook et al., 1989). Protein $(20 \mu \mathrm{g})$ from each treatment was loaded onto a $12.5 \%$

Table 1. Summary of mutant strains of ' $P$. butanovora' in which single amino acid substitutions were made to the $\alpha$-subunit of the $\mathrm{BMO}$ hydroxylase $(\mathrm{BMOH})$

For further details of mutants see Halsey et al. (2006).

\begin{tabular}{|lccl}
\hline Strain & $\begin{array}{c}\text { Targeted amino acid in } \\
\text { BMOH- } \boldsymbol{\alpha}^{*}\end{array}$ & $\begin{array}{c}\text { Corresponding amino acid in } \\
\text { MMOH- } \boldsymbol{\alpha}\end{array}$ & \multicolumn{1}{c|}{ Targeted region of amino acid substitution in BMOH- $\boldsymbol{\alpha}$} \\
\hline T148C & Thr 148 & Cys 151 & Near active site \\
G113N & Gly 113 & Asn 116 & Near active site \\
L279F & Leu 279 & Phe 282 & Hydrophobic cavity leading to active site \\
F321Y & Phe 321 & Tyr 324 & Surface of BMOH-believed to be involved in interaction with BMOB \\
Q320K & Glu 320 & Lys 323 & Surface of BMOH-believed to be involved in interaction with BMOB
\end{tabular}

${ }^{\star}$ The presumed position of amino acids is based upon homology to the MMOH- $\alpha$ subunit for which the crystal structure has been determined (Sazinsky \& Lippard, 2005). 
SDS-PAGE gel and resolved at $15 \mathrm{~mA}$. SDS-PAGE gels were stained with Coomassie blue to visualize the protein, destained and dried in a vacuum desiccator. The incorporation of ${ }^{14} \mathrm{C}$ label was visualized by phosphorimaging and the relative signal densities determined with the ImageQuant software provided by the manufacturer (Molecular Dynamics). A standard curve was prepared by diluting different amounts of ${ }^{14} \mathrm{C}_{2} \mathrm{H}_{2}$-labelled cell extracts into unlabelled cells extracts and comparing the intensities of the images obtained from the standards with the ${ }^{14} \mathrm{C}$-labelled experimental treatments.

Because complete inactivation of BMO did not occur following incubation with propionate, an experiment was carried out to discriminate between inactivation of a fraction of $\mathrm{BMO}$ versus a reduced turnover rate by all $\mathrm{BMO}$ molecules. The effect of propionate inactivation on ${ }^{14} \mathrm{C}_{2} \mathrm{H}_{2}$ label incorporation into $\mathrm{BMO}$ was examined. Butane-grown cells, washed and treated as described above, were exposed to either $10 \mathrm{mM}$ lactate or $10 \mathrm{mM}$ lactate plus $10 \mathrm{mM}$ propionate for $2 \mathrm{~h}$. Cells were washed and aliquots of each treatment were tested for BMO activity or incubated with $10 \mathrm{mM}$ lactate plus ${ }^{14} \mathrm{C}_{2} \mathrm{H}_{2}$ for $2 \mathrm{~h}$. Following incubation with ${ }^{14} \mathrm{C}_{2} \mathrm{H}_{2}$, whole-cell protein was examined by SDS-PAGE and the incorporation of ${ }^{14} \mathrm{C}$ into the $\alpha$ subunit polypeptide of BMO hydroxylase determined as described above.

Propionate inactivation of monooxygenases from other bacteria. Burkholderia cepacia G4 and Pseudomonas mendocina KR-1 were grown in the same medium as described for ' $P$. butanovora' with toluene $(1 \mathrm{mM})$ as the carbon source. Cultures were shaken at 200 r.p.m. on an orbital shaker at $30{ }^{\circ} \mathrm{C}$. The methanotrophic bacteria Methylosinus trichosporium OB3b and Methylococcus capsulatus (Bath), were grown under copper-limiting conditions in a $\mathrm{KNO}_{3}$ minimal salts medium to promote the production of sMMO rather than pMMO (Lee et al., 2006; Whittenbury et al., 1970). M. capsulatus (Bath) was incubated at $37{ }^{\circ} \mathrm{C}$ and $M$. trichosporium OB3b was incubated at $30{ }^{\circ} \mathrm{C}$ on an orbital shaker at 200 r.p.m. Monooxygenase activity was monitored with the ethene oxide assay described above.

\section{RESULTS}

\section{In vivo organic-acid-dependent inactivation of BMO}

Doughty et al. (2005) showed previously that acetate, propionate and butyrate are effective exogenous sources of reductant for supporting $\mathrm{BMO}$ activity in propane-grown cells of ' $P$. butanovora'. In this work it can be clearly seen that propionate $(10 \mathrm{mM})$ or butyrate $(10 \mathrm{mM})$ quickly and effectively reduced lactate-dependent $\mathrm{BMO}$ activity (Fig. 1). In contrast, the rate of lactate-dependent BMO activity was not affected when acetate $(10 \mathrm{mM})$ or an equivalent volume of phosphate buffer was added to the assay. The kinetics of propionate inactivation of BMO were unchanged even at concentrations as low as $0.1 \mathrm{mM}$, suggesting that the effect of propionate on $\mathrm{BMO}$ reaches saturation at concentrations below $0.1 \mathrm{mM}$. The same organic acids were tested to determine if the $\mathrm{BMO}$ inactivation was reversible or irreversible (Fig. 2). Propionate and butyrate irreversibly inactivated BMO in a time-dependent manner, and BMO activity was not completely restored when propionate or butyrate were removed (Fig. 2). In contrast, BMO activity did not decrease in cells treated with either lactate or a combination of lactate

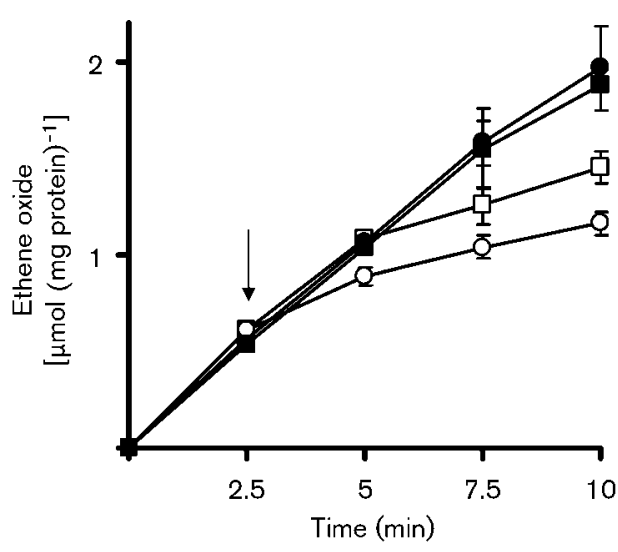

Fig. 1. Time-course of the effect of butyrate, propionate and acetate on the kinetics of lactate-dependent ethene oxidation. At time zero, vials containing propane-grown cells received $95 \mu \mathrm{M}$ ethene, and $10 \mathrm{mM}$ lactate was provided as an exogenous source of reductant. At the time indicated by the arrow, vials received either $10 \mu \mathrm{mol}(10 \mathrm{mM}$ in the assay vial) acetate ( $\boldsymbol{\square})$, propionate $(\bigcirc)$ or butyrate $(\square)$, or an equivalent volume $(10 \mu \mathrm{l})$ of buffer $(\bullet)$. Data points are the means of three replicates and error bars represent the standard deviation of the means.

and acetate. From data in Fig. 1 it was calculated that propionate had reduced BMO activity by $73-80 \%$ of its initial rate between 5 and $7.5 \mathrm{~min}$ after propionate addition. In contrast, Fig. 2 shows that only $40 \%$ of BMO was irreversibly inactivated following a similar length of incubation with propionate. These data suggest that propionate acts as both a reversible inhibitor and irreversible

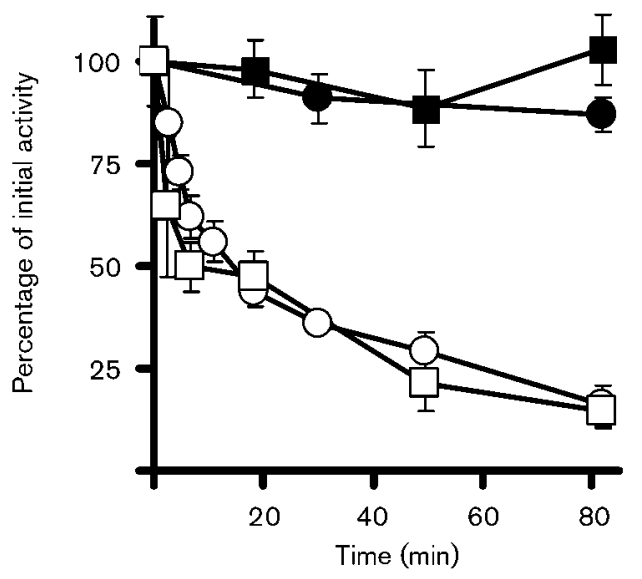

Fig. 2. Time-course of the irreversible effects of $10 \mathrm{mM}$ lactate $(\mathbf{O})$, or a combination of $10 \mathrm{mM}$ lactate and $10 \mathrm{mM}$ acetate ( $\boldsymbol{\square})$, propionate $(\bigcirc)$ or butyrate $(\square)$ on BMO activity. Cells were incubated for the length of time indicated on the $x$-axis, harvested, washed, and tested for residual BMO activity. Data points are the means of three replicates and error bars represent the standard deviation of the means. 
inactivator of BMO. The remainder of this study focused on the irreversible effect of propionate on BMO activity.

\section{The presence of butane and the absence of $\mathrm{O}_{2}$ protect BMO activity from the effect of propionate}

A series of experiments was carried out to characterize propionate-dependent BMO inactivation. When butane $(0.2 \mathrm{mM})$ was present in the assay, propionate $(10 \mathrm{mM})$ did not lead to a significant loss of BMO activity (Fig. 3a). Because BMO hydroxylation of butane is dependent upon $\mathrm{O}_{2}$ as a co-substrate we thought it worthwhile to determine if $\mathrm{O}_{2}$ was required for propionate-dependent $\mathrm{BMO}$ inactivation. Under anoxic conditions, propionate $(10 \mathrm{mM})$ failed to inactivate BMO (Fig. 3b). In contrast, when $22 \mathrm{nmol} \mathrm{O}_{2}$ was supplied to anoxic cells, the ability of propionate to inactivate $\mathrm{BMO}$ was restored. Control

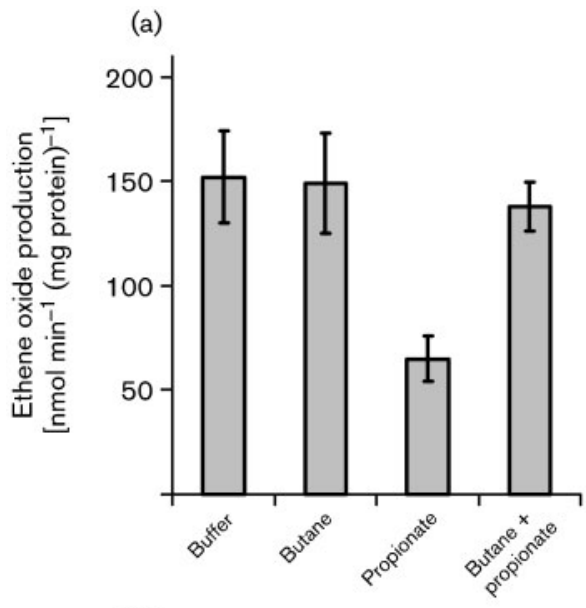

(b)

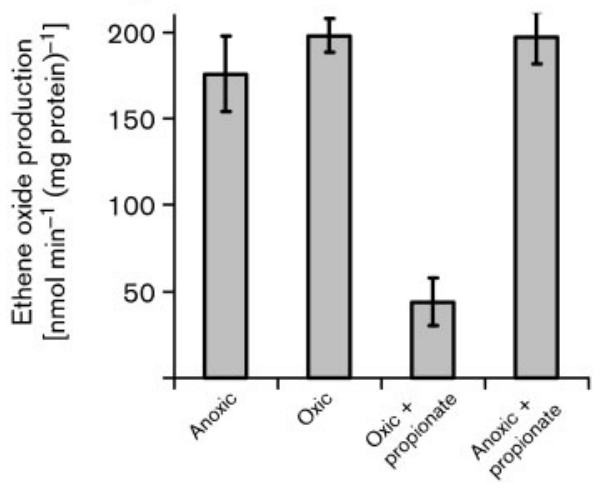

Fig. 3. Independently conducted experiments in which the irreversible inactivation of BMO by propionate was prevented by the inclusion of the enzyme's natural substrate, butane (a), or the removal of $\mathrm{O}_{2}$ (b), a co-substrate necessary for $\mathrm{BMO}$ catalytic turnover. Incubations were $30 \mathrm{~min}$ in length and lactate $(10 \mathrm{mM})$ was provided as an exogenous reductant. Data points are the means of three replicates and error bars represent the standard deviation of the means. treatments which received either no $\mathrm{O}_{2}$, or $\mathrm{O}_{2}$ and no propionate, did not show a significant decrease in $\mathrm{BMO}$ activity. Propionate-inactivated $\mathrm{BMO}$ did not regain activity following subsequent incubation under anoxic conditions, indicating that $\mathrm{BMO}$ activity was protected by anoxia, rather than restored during anoxic treatment. The $\mathrm{O}_{2}$-dependence of inactivation suggests that the catalytic cycle of BMO is involved in propionate-dependent inactivation.

\section{Determining the effect of protein synthesis on BMO activity}

Because the relative rates of $\mathrm{BMO}$ synthesis and turnover are unknown, we explored the possibility that propionatedependent BMO inactivation was due to repression of BMO synthesis. Chloramphenicol $\left(50 \mu \mathrm{g} \mathrm{ml}^{-1}\right)$ prevented the induction of BMO in repressed lactate-grown cells that were exposed to butane (data not shown). The kinetics of propionate-dependent inactivation of BMO were the same in chloramphenicol-treated and control cells, indicating that the decrease in $\mathrm{BMO}$ activity following exposure to propionate was mediated on pre-existing BMO.

\section{[2- ${ }^{14} \mathrm{C}$ ]Propionate and ${ }^{14} \mathrm{C}_{2} \mathrm{H}_{2}$ labelling experiments}

The possibility that propionate might covalently bind to $\mathrm{BMO}$ during inactivation was explored with $\left[2-{ }^{14} \mathrm{C}\right]$ propionate. Although SDS-PAGE analysis of cellular proteins following treatment with $\left[2-{ }^{14} \mathrm{C}\right]$ propionate showed weak labelling of a few polypeptides, the molecular masses of ${ }^{14} \mathrm{C}$-labelled bands did not correspond to the molecular masses of BMO polypeptides. The possibility was considered that propionate might label BMO in an SDS-labile manner. When cell extracts were electrophoresed on native polyacrylamide gels, they also failed to show any association of $\left[2-{ }^{14} \mathrm{C}\right]$ propionate with polypeptides of molecular masses equivalent to $\mathrm{BMO}$ hydroxylase or reductase (data not shown). These data suggest that $\left[2-{ }^{14}\right.$ C]propionate did not covalently bind to the BMO enzyme, and that propionate inactivation did not follow the model of a classical monooxygenase suicide substrate such as acetylene. Furthermore, we explored the possibility that propionate was oxidized by BMO. Propionate consumption by butane-grown ' $P$. butanovora' was unaffected by acetylene within the limits of detection [ $5 \mathrm{nmol}$ propionate $\left.\left.\min ^{-1}(\mathrm{mg} \text { protein })^{-1}\right)\right]$. These data further suggest that propionate is not a substrate of BMO.

Because propionate did not completely inactivate BMO, we attempted to distinguish between reduced $\mathrm{BMO}$ activity being due to inactivation of a fraction of BMO molecules versus a reduced rate of turnover of all BMO molecules. Butane-grown cells incubated with propionate for $2 \mathrm{~h}$ retained $\sim 10 \%$ of BMO activity, and all remaining BMO activity was found to be acetylene sensitive (Fig. 4a, b). Furthermore, the incorporation of ${ }^{14} \mathrm{C}$ from ${ }^{14} \mathrm{C}_{2} \mathrm{H}_{2}$ into 

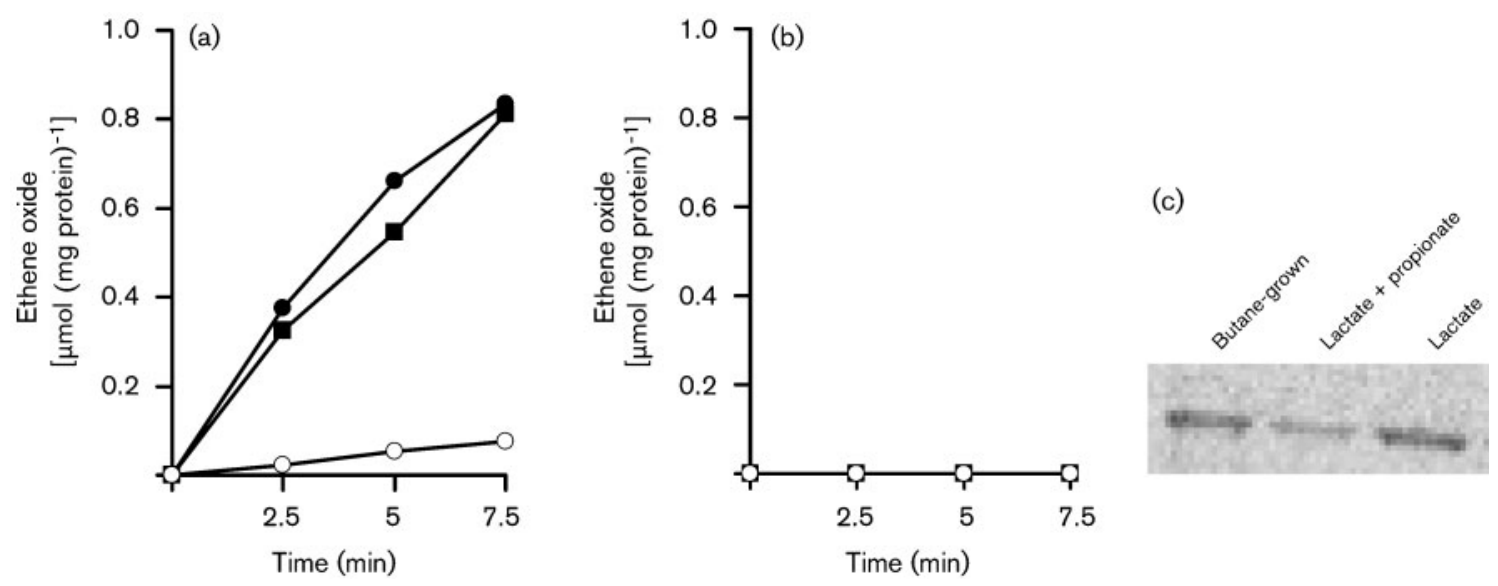

Fig. 4. ${ }^{14} \mathrm{C}_{2} \mathrm{H}_{2}$ labelling of propionate-treated cells. (a) Ethene oxide production by butane-grown cells ( $(0)$, and by butanegrown cells that were treated previously for $30 \mathrm{~min}$ with either lactate $(\boldsymbol{\square})$, or lactate and propionate $(\bigcirc)$. (b) Ethene oxide production by the same cells following an additional $2 \mathrm{~h}$ incubation with acetylene. (c) ${ }^{14} \mathrm{C}_{2} \mathrm{H}_{2}$-dependent labelling of the $\alpha$ subunit of the BMO enzyme in cells treated as described in (a), washed, and treated for $2 \mathrm{~h}$ with ${ }^{14} \mathrm{C}_{2} \mathrm{H}_{2}$.

the $58 \mathrm{kDa}$ polypeptide of the $\alpha$-subunit of BMO hydroxylase was reduced by $\sim 90 \%$ relative to the buffer control, and was consistent with the propionate-dependent reduction of BMO activity (Fig. 4c). These data suggest that propionate caused BMO inactivation rather than an overall reduction in the rate of BMO turnover.

\section{Inactivation of BMO in ' $P$. butanovora' mutants strains containing specific amino acid substitutions in the $\alpha$-subunit of the BMO hydroxylase}

Mutant strains of ' $P$. butanovora' that contain single amino acid substitutions in the $\alpha$-subunit of BMO hydroxylase $(\mathrm{BMOH}-\alpha)$ were examined for propionate-dependent inactivation of BMO (Table 2). The effects of propionate on BMO differed among the mutant strains. For example, in the case of the G113N mutant, in which a glycine was replaced by an asparagine residue in a region adjacent to, or contributing to, the active site, BMO activity was not inactivated by propionate. In contrast, mutant strain $\mathrm{T} 148 \mathrm{C}$, in which a threonine in the active-site region was replaced by a cysteine, showed a significant increase in propionate-dependent inactivation of $\mathrm{BMO}$ relative to wild-type. Mutants F321Y and L279F, which were modified at amino acid positions believed to be involved in the interaction of $\mathrm{BMOH}-\alpha$ with $\mathrm{BMOB}$, were inactivated by propionate to a similar extent as wild-type. Interestingly, reversible inhibition of BMO was observed in all mutant strains, including the G113N mutant. Inhibition of BMO activity by propionate in the G113N mutant was timedependent, and a $10 \mathrm{~min}$ incubation with propionate was sufficient to inhibit $\sim 50 \%$ of BMO activity. Propionatetreated G113N mutant regained BMO activity equivalent to the untreated cells following the washing procedure.

\section{Survey of other monooxygenases for propionate- dependent inactivation}

We explored the possibility that other well-studied monooxygenase enzymes that are closely related to BMO might be inactivated by fatty acids. In vivo studies showed that the diiron methane monooxygenases (sMMO) of Methylococcus capsulatus Bath and Methylosinus trichosporium OB3b, and the toluene o-monooxygenase of Burkholderia cepacia G4, were not inactivated by propionate. In contrast, the toluene 4-monooxygenase $\left(\mathrm{T}_{4} \mathrm{MO}\right)$ of Pseudomonas mendocina KR1 was inactivated following a

Table 2. Effect of propionate on BMO activity in ' $P$. butanovora' mutant strains in the $\alpha$-subunit of BMO hydroxylase

\begin{tabular}{|lrcc|}
\hline $\begin{array}{l}\text { 'P. butanovora' } \\
\text { strain }\end{array}$ & Sp. act & \multicolumn{2}{c|}{ BMO activity remaining (\%) $\dagger$} \\
\cline { 2 - 4 } & & Control $\$$ & Propionate treated $\$$ \\
\hline Wild-type & 155 & $96(15)$ & $41(7)$ \\
G113N & 44 & $92(20)$ & $103(16)$ \\
T148C & 98 & $102(11)$ & $15(3)$ \\
L279F & 101 & $90(9)$ & $56(8)$ \\
F321Y & 163 & $97(9)$ & $61(5)$ \\
Q320K & 56 & $104(8)$ & $28(3)$ \\
\hline
\end{tabular}

${ }^{\star}$ Rate of lactate-dependent ethene oxide formation $\left[\mathrm{nmol} \mathrm{min}^{-1}(\mathrm{mg}\right.$ protein $)^{-1}$ ] before propionate treatment.

†Values represent the mean of three replicates; the standard deviations of the means are shown in parentheses.

‡Cells were incubated in $50 \mathrm{mM}$ phosphate buffer with $10 \mathrm{mM}$ lactate for $30 \mathrm{~min}$.

$\S$ Cells were incubated in $50 \mathrm{mM}$ phosphate buffer with $10 \mathrm{mM}$ lactate and $10 \mathrm{mM}$ propionate for $30 \mathrm{~min}$. 
10 min incubation with $10 \mathrm{mM}$ propionate or butyrate by about 60 and $94 \%$ respectively. In contrast, acetate or lactate did not inactivate $\mathrm{T}_{4} \mathrm{MO}$ activity, indicating that $\mathrm{T}_{4} \mathrm{MO}$ was sensitive to the same range of organic acids as BMO. Furthermore, $\mathrm{T}_{4} \mathrm{MO}$ activity was protected from propionate-dependent inactivation by toluene, the physiological substrate of $\mathrm{T}_{4} \mathrm{MO}$ (data not shown).

\section{DISCUSSION}

The current study provided an unexpected and novel finding, that intermediate chain-length fatty acids inactivate BMO. Because some, but not all, of the BMO activity could be recovered when cells were washed to remove propionate, we were able to provide convincing evidence that both reversible inhibition and inactivation of BMO occurred. Furthermore, propionate-dependent inactivation of BMO was not observed in one mutant strain of ' $P$. butanovora' in which glycine 113 (thought to be close to the catalytic site on the $\alpha$-subunit of BMO hydroxylase) was changed to an asparagine residue. Because the reversible inhibition by propionate remained unaffected in this mutant, these data indicated that reversible inhibition and irreversible inactivation of BMO occur through separate mechanisms.

Propionate inhibition of BMO ties in well with the recent discovery that propionate represses the transcription of BMO genes (Doughty et al., 2006). We previously discussed a model of BMO transcriptional regulation to explain how fatty acid products of alkane oxidation might repress BMO. This form of feedback inhibition resembles the regulation of lipid synthesis (Fab) and fatty acid oxidation (Fad) characterized in Escherichia coli (Cronan \& Subrahmanyam, 1998). In this connection it is interesting to note that three Fab enzymes are not only repressed by long-chain acyl-CoAs at the level of transcription, but also controlled post-translationally through feedback inhibition by acylated acyl-carrier proteins (acyl-ACP) (Heath \& Rock, 1996; Marrakchi et al., 2002). The net result is close coupling of the reductant-consuming lipid biosynthesis pathway with reductant-generating fatty acid $\beta$-oxidation. Similarly, the inhibition of alkane oxidation by the downstream products of BMO activity could prevent the allocation of reductant to $\mathrm{BMO}$ under circumstances where the production of fatty acids via alkane oxidation exceeds the carbon and energy requirements of the cell. A physiological role for inactivation of BMO can also be envisaged, particularly if the monooxygenase turns over slowly, generates toxic $\mathrm{H}_{2} \mathrm{O}_{2}$ in the absence of substrate, and also continues to consume reductant.

Because we could not detect propionate consumption during BMO inactivation, and $\left[2-{ }^{14} \mathrm{C}\right]$ propionate label did not associate with the BMO polypeptides after electrophoresis under denaturing conditions, propionate inactivation did not follow the model of a monooxygenase suicide substrate such as acetylene. In the context of existing literature on sMMO, two possible mechanisms for propionate-dependent inactivation of $\mathrm{BMO}$ can be proposed. First, in vitro studies showed that when sMMO hydroxylase is electrically reduced at the surface of an electrode, $\mathrm{O}_{2}$ is reduced to $\mathrm{H}_{2} \mathrm{O}_{2}$ by the hydroxylase and subsequently inactivates it (Astier et al., 2003). We propose a model of $\mathrm{BMO}$ inactivation in which propionate stimulates the production of $\mathrm{H}_{2} \mathrm{O}_{2}$ by $\mathrm{BMO}$ and causes oxidative enzyme damage. Propionate-dependent formation of $\mathrm{H}_{2} \mathrm{O}_{2}$ by $\mathrm{BMO}$ would reconcile our observations that $\mathrm{BMO}$ inactivation is $\mathrm{O}_{2}$ - and turnover-dependent, while propionate oxidation per se does not occur. A model based upon the catalytic cycle of sMMO is shown in Fig. 5 (Brazeau et al., 2001; Lee et al., 1993a, b; Liu et al., 1995; Zhang \& Lipscomb, 2006). The diferric active site, shown at the bottom of the model, is reduced and used to break one bond of $\mathrm{O}_{2}$, forming intermediate $\mathrm{P}$. The scission of the second $\mathrm{O}_{2}$ bond results in the formation of intermediate Q. Alternatively, the reaction of the reduced form of sMMO with $\mathrm{O}_{2}$ can result in $\mathrm{H}_{2} \mathrm{O}_{2}$ formation and a return of sMMO to a diferric resting state (Zhang \& Lipscomb, 2006). Although the presence of the regulatory subunit (MMOB) eliminates the production of $\mathrm{H}_{2} \mathrm{O}_{2}$ by sMMO hydroxylase, $\mathrm{H}_{2} \mathrm{O}_{2}$ production resumed, as did enzyme inactivation, following the introduction of substrate to the reaction mixture (Astier et al., 2003). In this context, the aliphatic tail of propionate might resemble the alkane substrate of BMO sufficiently well to reduce the coupling of $\mathrm{O}_{2}$ activation to substrate oxidation and result in $\mathrm{H}_{2} \mathrm{O}_{2}$ formation. In this connection there is some indication that $\mathrm{BmoB}$ is not involved in the coupling of $\mathrm{O}_{2}$ activation to substrate turnover by BMO (Dubbels et al., 2007). In methane monooxygenase hydroxlyase ( $\mathrm{MMOH})$, multiple substrate-binding sites have been proposed for substrates larger than methane (Sazinsky \& Lippard, 2005), raising the possibility that butane and propionate compete

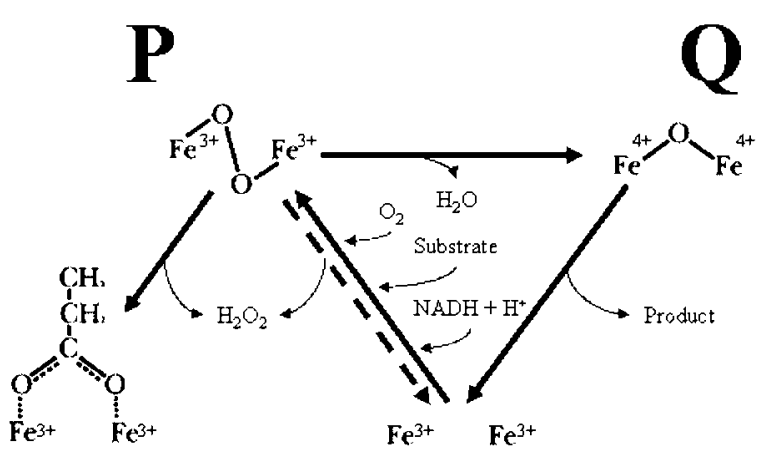

\section{Inactive BMO Enzyme}

Fig. 5. A model of propionate-dependent inactivation of BMO superimposed upon the catalytic cycle of sMMO (Brazeau et al., 2001). See text for details. 
for a site outside the substrate-binding pocket. Conceptually, this could reconcile our observations that (i) butane protects $\mathrm{BMO}$ from propionate and (ii) propionate is not oxidized by $\mathrm{BMO}$ (as propionate does not enter the active site). Our results, although preliminary, raise the possibility that alternative substrate-binding pockets have replaced the role of the coupling subunit in substrate recognition. Second, propionate may form an ionic bond with the active-site irons, and inactivate the enzyme by blocking the active site. In this context, it is interesting to note that crystallographic data obtained from the diferric form of sMMO showed an unidentified electron density within the hydrophobic substrate-binding pocket. Researchers tentatively identified this structure as acetate, a component of the crystallization buffer, with the carboxyl group of acetate forming a bridging ligand between the diirons (Rosenzweig et al., 1997). Additionally, recent research on a structurally related diiron desaturase used acetate as a molecular mimic for $\mathrm{O}_{2}$ binding. The authors suggested that acetate produced a carboxyl shift in a glutamate residue, resulting in a change in coordination of an active-site iron (Moche et al., 2003). Interestingly, a similar change was observed following the binding of substrate (acyl-ACP) and it is hypothesized that the observed change in iron coordination increases the reactivity of the active site with $\mathrm{O}_{2}$ (Moche et al., 2003). Our research, although preliminary and in vivo, raises the possibility that propionate could be useful as a probe to uncover some of the mechanistic details of BMO. Because of the novelty of propionate-dependent inactivation, we extended our study to mutant strains of ' $P$. butanovora' in which single amino acid substitutions had been made to the $\alpha$-subunit of the hydroxylase (Halsey et al., 2006). Because amino acids G113 and T148 are predicted to be close to the enzyme active site (Table 1), the altered outcome of propionate inactivation observed in mutant strains G113N and T148C suggests that propionate enters the active site of BMO. Although it remains unclear why mutant strains G113N and T148C display altered propionate-dependent inactivation relative to wild-type, two possibilities can be discussed. First, structural prediction programs indicate that the size of the hydrophobic substrate-binding cavity of BMO will be decreased by the $\mathrm{G} \rightarrow \mathrm{N}$ mutation and increased by the $\mathrm{T} \rightarrow \mathrm{C}$ mutation (Halsey et al., 2006). In this context, the insensitivity of mutant strain G113N to propionate may indicate that the active site of the enzyme is inaccessible to propionate. In contrast, the larger substrate-binding cavity of T148C may increase the accessibility of the active site to propionate. Second, the altered outcome of propionate-dependent inactivation in the mutant strains might reflect a subtle change in the tendency of these enzymes to release $\mathrm{H}_{2} \mathrm{O}_{2}$. Indeed, recent research on a structurally related diiron desaturase indicated that a mutant form of the enzyme containing a single amino acid substitution near the active site produced 40 -fold more $\mathrm{H}_{2} \mathrm{O}_{2}$ than the wild-type enzyme (Guy et al., 2006). Clearly, we are in a position to move forward and obtain crystal structures of BMO from both the wild-type and mutant strains, and carry out in vitro studies with the recently purified BMO (Dubbels et al. 2007) to gain a better understanding of short-chain fatty acid inactivation.

\section{ACKNOWLEDGEMENTS}

This research was supported by a grant from the US Environmental Protection Agency-sponsored Western Region Hazardous Substance Research Center under agreement R-828772, the National Institute of Health Grant no. 5RO1 GM56128-06, and the Oregon Agricultural Experiment Station. D. M. D. acknowledges partial financial support of a Janet Ford Fellowship from the Department of Microbiology.

\section{REFERENCES}

Arp, D. J. (1999). Butane metabolism by butane-grown 'Pseudomonas butanovora'. Microbiology 145, 1173-1180.

Astier, Y., Balendra, S., Hill, H. A., Smith, T. J. \& Dalton, H. (2003). Cofactor-independent oxygenation reactions catalyzed by soluble methane monooxygenase at the surface of a modified gold electrode. Eur J Biochem 270, 539-544.

Brazeau, B. J., Austin, R. N., Tarr, C., Groves, J. T. \& Lipscomb, J. D. (2001). Intermediate $Q$ from soluble methane monooxygenase hydroxylates the mechanistic substrate probe norcarane: evidence for a stepwise reaction. J Am Chem Soc 123, 11831-11837.

Cronan, J. E., Jr \& Subrahmanyam, S. (1998). FadR, transcriptional co-ordination of metabolic expediency. Mol Microbiol 29, 937-943.

Doughty, D. M., Sayavedra-Soto, L. A., Arp, D. J. \& Bottomley, P. J. (2005). Effects of dichloroethene isomers on the induction and activity of butane monooxygenase in the alkane-oxidizing bacterium "Pseudomonas butanovora". Appl Environ Microbiol 71, 6054-6059.

Doughty, D. M., Sayavedra-Soto, L. A., Arp, D. J. \& Bottomley, P. J. (2006). Product repression of alkane monooxygenase expression in Pseudomonas butanovora. J Bacteriol 188, 2586-2592.

Dubbels, B. L., Sayavedra-Soto, L. A. \& Arp, D. J. (2007). Butane monooxygenase of 'Pseudomonas butanovora': purification and biochemical characterization of a terminal-alkane hydroxylating diiron monooxygenase. Microbiology 153, 1808-1816.

Gornall, A. G., Bardawill, C. J. \& David, M. M. (1949). Determination of serum proteins by means of the biuret reaction. J Biol Chem 177, 751-766.

Green, J., Prior, S. D. \& Dalton, H. (1985). Copper ions as inhibitors of protein $\mathrm{C}$ of soluble methane monooxygenase of Methylococcus capsulatus (Bath). Eur J Biochem 153, 137-144.

Guy, J. E., Abreu, I. A., Moche, M., Lindqvist, Y., Whittle, E. \& Shanklin, J. (2006). A single mutation in the castor $\Delta^{9}$-18:0-desaturase changes reaction partitioning from desaturation to oxidase chemistry. Proc Natl Acad Sci U S A 103, 17220-17224.

Halsey, K. H., Sayavedra-Soto, L. A., Bottomley, P. J. \& Arp, D. J. (2006). Site-directed amino acid substitutions in the hydroxylase alpha subunit of butane monooxygenase from Pseudomonas butanovora: implications for substrates knocking at the gate. J Bacteriol 188, 4962-4969.

Hamamura, N., Storfa, R. T., Semprini, L. \& Arp, D. J. (1999). Diversity in butane monooxygenases among butane-grown bacteria. Appl Environ Microbiol 65, 4586-4593.

Heath, R. J. \& Rock, C. O. (1996). Inhibition of beta-ketoacyl-acyl carrier protein synthase III $(\mathrm{FabH})$ by acyl-acyl carrier protein in Escherichia coli. J Biol Chem 271, 10996-11000. 
Hyman, M. R. \& Arp, D. J. (1992). ${ }^{14} \mathrm{C}_{2} \mathrm{H}_{2}$ - and ${ }^{14} \mathrm{CO}_{2}$-labeling studies of the de novo synthesis of polypeptides by Nitrosomonas europaea during recovery from acetylene and light inactivation of ammonia monooxygenase. J Biol Chem 267, 1534-1545.

Jahng, D. \& Wood, T. K. (1996). Metal ions and chloramphenicol inhibition of soluble methane monooxygenase from Methylosinus trichosporium OB3b. Appl Microbiol Biotechnol 45, 744-749.

Lee, S. K., Fox, B. G., Froland, W. A., Lipscomb, J. D. \& Münck, E. (1993a). A transient intermediate of the methane monooxygenase catalytic cycle containing a $\mathrm{Fe}^{\mathrm{IV}} \mathrm{Fe}^{\mathrm{IV}}$ cluster. J Am Chem Soc 115, 6450-6451.

Lee, S. K., Nesheim, J. C. \& Lipscomb, J. D. (1993b). Transient intermediates of the methane monooxygenase catalytic cycle. J Biol Chem 268, 21569-21577.

Lee, S. W., Keeney, D. R., Lim, D. H., Dispirito, A. A. \& Semrau, J. D. (2006). Mixed pollutant degradation by Methylosinus trichosporium OB3b either soluble or particulate methane monooxygenase: can the tortoise beat the hare? Appl Environ Microbiol 72, 7503-7509.

Lipscomb, J. D. (1994). Biochemistry of the soluble methane monooxygenase. Annu Rev Microbiol 48, 371-399.

Liu, K. E., Valentine, A. M., Qui, D., Edmondson, D. E., Appelman, E. H., Spiro, T. G. \& Lippard, S. J. (1995). Characterization of a diiron(III) peroxo intermediate in the reaction cycle of methane monooxygenase hydroxylase from Methylococcus capsulatus (Bath). J Am Chem Soc 117, 4997-4998.

Marrakchi, H., Zhang, Y. M. \& Rock, C. O. (2002). Mechanistic diversity and regulation of type II fatty acid synthesis. Biochem Soc Trans 30, 1050-1055.

Moche, M., Shanklin, J., Ghoshal, A. \& Lindqvist, Y. (2003). Azide and acetate complexes plus two iron-depleted crystal structures of the diiron enzyme $\Delta^{9}$ stearoyl-acyl carrier protein desaturase, implications for oxygen activation and catalytic intermediates. J Biol Chem 278 , 25072-25080.

Prior, S. D. \& Dalton, H. (1985). Acetylene as a suicide substrate and active site probe for methane monooxygenase from Methylococcus capsulatus (Bath). FEMS Microbiol Lett 29, 105-109.

Rosenzweig, A. C., Brandstetter, H., Whittington, D. A., Nordlund, P., Lippard, S. J. \& Frederick, C. A. (1997). Crystal structures of the methane monooxygenase hydroxylase from Methylococcus capsulatus
(Bath): implications for substrate gating and component interactions. Proteins 29, 141-152.

Sambrook, J., Fritsch, E. F. \& Maniatis, T. (1989). Molecular Cloning: a Laboratory Manual, 2nd edn. Cold Spring Harbor, NY: Cold Spring Harbor Laboratory.

Sayavedra-Soto, L. A., Byrd, C. M. \& Arp, D. J. (2001). Induction of butane consumption in Pseudomonas butanovora. Arch Microbiol 176, 114-120.

Sayavedra-Soto, L. A., Doughty, D. M., Kurth, E. G., Bottomley, P. J. \& Arp, D. J. (2005). Product and product-independent induction of butane oxidation in Pseudomonas butanovora. FEMS Microbiol Lett 250, 111-116.

Sazinsky, M. H. \& Lippard, S. J. (2005). Product bound structures of the soluble methane monooxygenase hydroxylase from Methylococcus capsulatus (Bath): protein motion in the alpha-subunit. J Am Chem Soc 127, 5814-5825.

Sluis, M. K., Sayavedra-Soto, L. A. \& Arp, D. J. (2002). Molecular analysis of the soluble butane monooxygenase from 'Pseudomonas butanovora'. Microbiology 148, 3617-3629.

Smith, T. J. \& Dalton, H. (2004). Biocatalysis by methane monooxygenase and its implications for the petroleum industry. In Petroleum Biotechnology, Developments and Perspectives, pp. 177-192. Edited by R. Vazquez-Duhalt \& R. Qintero-Ramirez. Amsterdam: Elsevier.

Smith, C. A., O'Reilly, K. T. \& Hyman, M. R. (2003). Cometabolism of methyl tertiary butyl ether and gaseous $\mathrm{n}$-alkanes by Pseudomonas mendocina KR-1 grown on C5-C8 n-alkanes. Appl Environ Microbiol 69, 7385-7394.

Vangnai, A. S. \& Arp, D. J. (2001). An inducible 1-butanol dehydrogenase, a quinohaemoprotein, is involved in the oxidation of butane by 'Pseudomonas butanovora'. Microbiology 147, 745-756.

Whittenbury, R., Phillips, K. C. \& Wilkinson, J. F. (1970). Enrichment, isolation and some properties of methane-utilizing bacteria. J Gen Microbiol 61, 205-218.

Zhang, J. \& Lipscomb, J. D. (2006). Role of the C-terminal region of the B component of Methylosinus trichosporium OB3b methane monooxygenase in the regulation of oxygen activation. Biochemistry 45, 1459-1469.

Edited by: J. A. Vorholt 